\title{
Candida species isolated from the vaginal mucosa of HIV-infected women in Salvador, Bahia, Brazil
}

\begin{abstract}
Background: Vulvovaginal candidiasis (VVC) is the second most common vaginal infection. HIV-infection is a risk factor for this infection. Objective: To determine the frequency of VVC and to describe the main Candida species isolated and their susceptibility to antifungal drugs in HIV-infected patients, compared to HIV-uninfected women in Salvador, Brazil. Methods: Cross-sectional study including a group of 64 HIV-infected women and 76 uninfected women, followed up at the AIDS reference center and at the Gynecological Clinic of Escola Bahiana de Medicina e Saúde Pública (Salvador, Bahia, Brazil). Results: Frequency of Candida spp. was higher in HIV-infected women (29.7\%) than in HIV-uninfected controls (14.5\%) $(\mathrm{p}=0.02)$. The odds ratio value for vulvovaginal candidiasis in HIV-infected patients was 2.6 (95\% CI: $1.07-6.32 \mathrm{p}=0.03$ ). Candida albicans was the most commonly isolated species in both HIV-infected $(52.3 \%)$ and uninfected women (85.7\%), followed by C. parapsolis in $17.6 \%$ and $14.3 \%$, respectively. In HIV-infected women, C. glabrata, C. parapsilosis, and a coinfection of C. albicans and C. glabrata were also identified. There was no significant difference between Candida species isolated from the vaginal mucosa of women with VVC and colonization of the vaginal mucosa of HIV-infected and HIV-uninfected women. One C. glabrata isolate from an HIV-infected patient was resistant to fluconazole and other two isolates exhibited a dose-dependent susceptibility. Conclusion: Our results confirm a higher frequency of Candida spp. isolated from the vaginal mucosa of HIV-infected women and a broader spectrum of species involved. Only Candida glabrata isolates showed decreased susceptibility to fluconazole.
\end{abstract}

Keywords: HIV; Candida; candidiasis, vulvovaginal.

[Braz J Infect Dis 2011;15(3):239-244] @Elsevier Editora Ltda.

\section{INTRODUCTION}

Vulvovaginal candidiasis (VVC) is one of the most frequent vaginal infections in the world. ${ }^{1,2}$ It is estimated that $75 \%$ of women will have VVC at least once in their lifetime. ${ }^{3,4}$ Clinical signs and symptoms of this infection include itching, white discharge, edema, and erythema of the vulva. ${ }^{4-6}$ Candida albicans, a saprophyte present in the vaginal mucosa, is isolated in $80 \%$ of VVC cases. ${ }^{7,8}$ Factors which predispose to VVC include: pregnancy, uncontrolled diabetes mellitus, corticosteroids or systemic/ vaginal antibiotic therapy, HIV infection, and Candida vaginal colonization (CVC). ${ }^{9,10}$

The frequency of VVC caused by other Candida species, such as Candida tropicalis, Candida glabrata, and Candida krusei is increasing, especially in HIV-infected women. ${ }^{5,8,11}$ C. albicans and C. glabrata are responsible for the majority of VVC cases in HIV-infected women. ${ }^{10,12}$ Although resistance to azoles antifungal therapy is rare in C. albicans isolates (1\%), it is becoming commonplace among C. glabra$\mathrm{ta}$ isolates (up to 15\%) as well as among other non-albicans species. ${ }^{5,10,13,14}$

Few studies in Brazil have assessed the prevalence of VVC in HIV-infected women undergoing highly active antiretroviral therapy (HAART) treatment. ${ }^{15}$ The aim of this study was to determine the frequency of VVC and to describe the main Candida species isolated in HIV-infected patients, compared to HIV-uninfected women in Salvador, Brazil. In addition, the susceptibility of Candida species to antifungal drugs was evaluated.
Authors

Paula Matos Oliveira

Rita Elizabeth

Mascarenhas 2

Claire Lacroix ${ }^{3}$

Suzana Ramos Ferrer ${ }^{2}$ Rone Peterson C Oliveira ${ }^{4}$ Elaine Andrade Cravo ${ }^{5}$ André P Ribeiro Alves 5 Maria Fernanda Rios Grassi $^{6}$

'Obstetrics and Gynecology Specialist; PhD student of Postgraduate Program on Medicine and Human Health, Escola Bahiana de Medicina e Saúde Pública (EBMSP), Salvador, Bahia, Brazil

${ }^{2} \mathrm{PhD}$; Professor of Microbiology, EBMSP, Salvador, Bahia, Brazil ${ }^{3} \mathrm{PhD}$; Laboratoire de Mycologie-Parasitologie, Paris, France

${ }^{4} \mathrm{MSc}$; Gynecology Assitant Professor, EBMSP, Salvador Bahia, Brazil

${ }^{5}$ Scientific initiation student, EBMSP, Salvador, Bahia, Brazil

${ }^{6} \mathrm{PhD}$; Chief of Laboratório Avançado de Saúde Pública, FIOCRUZ, Bahia, Brazil

Submitted on: 11/17/2010 Approved on: 02/17/2011

Correspondence to: Maria Fernanda Rios Grassi

Rua Waldemar Falcão, 121 Candeal - Salvador (BA) Brazil 40296-710

Phone: +55 71 3176-2200 Fax: +55 $713176-2327$ grassi@bahia.fiocruz.br

We declare no conflict of interest. 


\section{MATERIAL AND METHODS}

\section{Study population and procedure}

A group of sixty-four HIV-infected women receiving care at the AIDS reference center of Bahia (Centro Especializado em Diagnóstico, Assistência e Pesquisa, CEDAP) and 76 HIV-uninfected women from the Gynecology Clinic of Escola Bahiana de Medicina e Saúde Pública (Salvador, Bahia, Brazil) were included in this study, between May 2006 and May 2007.

Patients were sequentially enrolled at the moment of the medical appointment. Inclusion criteria were women aged more than 18 years old, sexually active, positive serology for HIV (HIV group) or negative (control group). Exclusion criteria were: pregnancy or post-partum, intra-vaginal treatment thirty days prior to vaginal collection, vaginal bleeding, sexual intercourse or vaginal douching within the 48 hours preceding vaginal sample collection.

The study was approved by the Institutional Research Boarding of the Fundação Oswaldo Cruz Bahia (Fiocruz - Bahia). All patients signed an informed consent form prior to admission.

\section{Specimen collection}

Demographic and clinical data were obtained by specific standardized data collection forms. CD4+ T lymphocytes count and HIV viral load values were obtained from medical records. Vaginal samples were collected with sterile swabs, during gynecological examination. Samples were cultured on Sabouraud's agar (BD-Difco), incubated at $35^{\circ} \mathrm{C}$ for $48 \mathrm{~h}$, and a direct examination was performed. Yeasts isolates were sub-cultured on CHROMagar Candida (Beckton Dickinson) in order to identify C. albicans and mixtures of yeasts. All C. albicans isolates were screened with Bichro-Dubli ${ }^{\circledR}(\mathrm{Fu}-$ mouze) in order to identify C. dubliniensis. Other Candida species were identified with ID32CAux ${ }^{\oplus}$ (BioMérieux). Minimal inhibitory concentrations (MICs) were determined by the E-Test ${ }^{\oplus}$ method with C. parapsilosis ATCC 22019 as control. After 24 hours of incubation, an elliptical zone of inhibition was produced and the point at which the ellipse meets the strip gives a reading for the MIC of the drug.

Candida vaginal colonization was defined as culture isolation of yeasts from asymptomatic women. Women with a positive culture were considered to have VVC if they reported symptoms (vaginal itching, burning, and/or discharge) at the time of the medical appointment.

\section{Statistical analysis}

Frequencies of Candida spp. of HIV-infected women were compared to those of the control group by using $t$ tests for continuous variables and Chi-square tests or Fisher's exact test for categorical variables. A mul- tiple logistic regression model was used to evaluate the prediction capacity of each independent variable in the occurrence of the expected condition. Unadjusted odds ratios (ORs) were initially calculated to screen for inclusion in the multivariate model; variables that exhibited at least moderate association $(\mathrm{p}=0.10)$ with the outcome in the presence of these design variables were considered for inclusion in the final models. Statistical analysis was done with the SPSS (Statistical Package for the Social Sciences) 13.0.

\section{RESULTS}

The median age of HIV-infected patients was similar to that of the uninfected control group. Age at time of first sexual intercourse was lower in HIV-infected women (16.2 \pm 4.0 years) compared to the control group $(17.5 \pm 3.9$ years $)$ $[\mathrm{p}=0.05]$. The number of lifetime sexual partners and the frequency of reported sexually transmitted diseases were significantly higher in the HIV-infected group, compared to uninfected patients. Thirty-four HIV-infected women (56.3\%) were treated with HAART. The mean CD4+ T lymphocytes count was $644 \pm 551$ cells $/ \mathrm{mm}^{3}$ and mean HIV viral load was $3.9 \pm 4.3 \log _{10}$ copies $/ \mathrm{mL}$.

Candida spp. isolation from the vaginal mucosa was more frequent in HIV-infected patients (29.7\%), compared to uninfected women $(14.5 \%)(\mathrm{p}=0.02)$. However, the frequency of VVC and Candida spp. colonization were similar in both HIV-infected and uninfected women $(\mathrm{p}=0.95)$ (Table 1). The odds ratio value for the presence of Candida spp. in vaginal mucosa of HIV-infected patients was 2.6 (95\% CI: $1.07-6.32, \mathrm{p}=0.03)$, after adjusting for variables (Table 2).

Candida spp. identification was possible in 24 vaginal samples (17 from HIV-infected patients and 7 from uninfected women) (Table 3). C. albicans was the most frequent species isolated in both HIV-infected (52.9\%) and uninfected women (85.7\%). In HIV-infected women were also identified the following species: C. glabrata, $C$. parapsilosis, C. dubliniensis and a coinfection of C. albicans and C. glabrata. In the HIV-uninfected group, the only species isolated were C. albicans and C. parapsilosis.

In both HIV-infected and uninfected women, there was no significant difference observed in the frequency of a particular species of Candida isolated from the vaginal mucosa and the presence of VVC, nor was there a difference in the frequency of a particular species of Candida colonizing the vaginal mucosa (Table 4).

Only one out of 24 yeast isolates, an isolate of C. glabrata from an HIV-infected patient, was resistant to fluconazole (MIC $>256 \mathrm{mg} / \mathrm{L}$ ). Two C. glabrata isolates exhibited a dose-dependent susceptibility to fluconazole $(\mathrm{MIC}=24$ and $48 \mathrm{mg} / \mathrm{L})$ (Table 5). 


\begin{tabular}{|c|c|c|c|c|c|}
\hline & \multicolumn{2}{|c|}{$\begin{array}{l}\text { HIV-infected group }(n=64) \\
n\end{array}$} & \multicolumn{2}{|c|}{$\begin{array}{l}\text { HIV-uninfected group }(n=76) \\
n\end{array}$} & \multirow{2}{*}{$\begin{array}{c}\mathbf{p} \\
0.07 \\
\end{array}$} \\
\hline Age (years) $)^{*}$ & 64 & $30.4 \pm 6$ & 76 & $28.7 \pm 6$ & \\
\hline \multicolumn{6}{|l|}{ Marital status (n, \%) } \\
\hline Married/cohabiting & 34 & 53.1 & 47 & 61.8 & 0.29 \\
\hline Unmarried/non-cohabiting & 30 & 46.9 & 29 & 38.2 & 0.29 \\
\hline \multicolumn{6}{|l|}{ Education (n, \%) } \\
\hline$<8$ years & 40 & 62.5 & 26 & 34.2 & 0.001 \\
\hline$>8$ years & 24 & 37.5 & 50 & 65.8 & 0.001 \\
\hline \multicolumn{6}{|l|}{ Family income (n, \%) } \\
\hline$<\$ 240 /$ month & 48 & 75 & 34 & 44.7 & $<0.001$ \\
\hline$\geq \$ 240 /$ month & 16 & 25 & 42 & 55.3 & $<0.001$ \\
\hline \multicolumn{6}{|l|}{ Sexual and obstetric history } \\
\hline Age of first intercourse $\mathrm{e}^{\#}$ & 64 & $16.2 \pm 4.0$ & 76 & $17.5 \pm 3.9$ & 0.05 \\
\hline No. of partners & 64 & $8.3 \pm 13.4$ & 76 & $3.6 \pm 4.3$ & $<0.01$ \\
\hline STD history (n, \%) & 26 & $40.6 \%$ & 10 & 13.2 & $<0.01$ \\
\hline No. of deliveries & 64 & $1.7 \pm 1.2$ & 76 & $1.3 \pm 1.2$ & 0.02 \\
\hline Users of HAART & 38 & $59.4 \%$ & - & - & NA \\
\hline T CD4+ count & 64 & $644 \pm 551$ & - & - & NA \\
\hline Viral load & 64 & $3.9 \pm 4.3$ & - & - & NA \\
\hline Vaginal Candida spp. (n) & 19 & 29.7 & 11 & 14.5 & 0.02 \\
\hline Candida spp. colonization & 5 & 26.3 & 3 & 27.3 & 0.95 \\
\hline VVC & 14 & 73.7 & 8 & 72.7 & 0.95 \\
\hline
\end{tabular}

SD, standard deviation; NA, not applicable. STD, sexually transmitted disease. HAART, highly active antiretroviral therapy; CD4: cells/mm; ; viral load: $\log 10$ copies $/ \mathrm{mL} . \mathrm{p}<0.05, \chi^{2}$ test, Student's $t$ test.

* mean $\pm \mathrm{SD}$

Table 2. Adjusted odds ratio for Candida spp. presence in HIV infected women

\begin{tabular}{lccc} 
Variables & Adjusted OR & IC 95\% & $\mathbf{p}$ \\
\hline HIV infection & 2.61 & $1.07-6.32$ & 0.03 \\
\hline Age & 1.00 & $0.92-1.08$ & 0.98 \\
\hline Years of schooling & 0.89 & $0.78-1.02$ & 0.1 \\
\hline Family income & 0.97 & $0.7-1.33$ & 0.86 \\
\hline $\begin{array}{l}\text { First sexual } \\
\text { intercourse }\end{array}$ & 1.02 & $0.91-1.14$ & 0.73 \\
\hline $\begin{array}{l}\text { Condom use } \\
\text { Number of sexual } \\
\text { partners }\end{array}$ & 0.82 & $0.27-2.43$ & 0.72 \\
\hline STD history & 0.99 & $0.95-1.04$ & 0.9 \\
\hline
\end{tabular}

Adjusted variables: HIV infection, age, years of schooling, family income, first sexual intercourse, condom use, number of sexual partners, STD history. OR, odds ratio. $\mathrm{p}<0.05$. Multiple logistical regression.

\section{DISCUSSION}

This study assessed for the first time the prevalence of VVC and the main Candida species found in vaginal mucosa of HIV-infected women, in Salvador-Bahia, Brazil. The main finding of our study was the higher frequency of Candida spp. in vaginal mucosa of HIV-infected women than HIV-uninfected, but the frequency of VVC was similar in both groups. These results were expected since the majority of the HIV-infected patients enrolled in this study were on HAART and had CD4+ T-cell counts higher than 500 cells $/ \mathrm{mm}^{3}$. Indeed, the risk of colonization with Candida species in HIV-infected women with CD4+ T-cell counts below 200 cells $/ \mathrm{mm}^{3}$ is three times higher, compared to immunocompetent HIV-infected or HIV-uninfected women. ${ }^{16,17}$ Similar prevalence of VVC (23.5\%) was found in patients from a cohort of 458 HIV-infected patients under antiretroviral therapy followed in Rio de Janeiro-Brazil. However, the authors did not identify species of Candida and there was no 
Table 3. Frequency of Candida species isolated from the vaginal mucosa of HIV-infected and uninfected women

\begin{tabular}{|c|c|c|c|c|c|}
\hline \multirow[b]{2}{*}{ Isolated species } & \multicolumn{2}{|c|}{$\begin{array}{l}\text { HIV-infected women } \\
\qquad \mathrm{n}=17\end{array}$} & \multicolumn{2}{|c|}{$\begin{array}{l}\text { HIV-uninfected women } \\
\qquad \mathbf{n}=7\end{array}$} & \multirow[b]{2}{*}{$\mathrm{p}=0.56$} \\
\hline & $\mathbf{n}$ & $\%$ & $\mathbf{n}$ & $\%$ & \\
\hline C. albicans & 9 & 52.9 & 6 & 85.7 & \\
\hline C. parapsilosis & 3 & 17.6 & 1 & 14.3 & \\
\hline C. glabrata & 3 & 17.6 & 0 & 0 & \\
\hline C. dubliniensis & 1 & 5.9 & 0 & 0 & \\
\hline C. albicans and C. glabrata & 1 & 5.9 & 0 & 0 & \\
\hline
\end{tabular}

$\mathrm{p}<0.05, \chi^{2}$ test.

Table 4. Frequency of vulvovaginal candidiasis and colonization with Candida species from the vaginal mucosa of HIV-infected and uninfected women

\begin{tabular}{|c|c|c|c|c|}
\hline \multirow{3}{*}{ Candida species } & \multicolumn{2}{|c|}{$\begin{array}{c}\text { HIV-infected } \\
\text { n }=17\end{array}$} & \multicolumn{2}{|c|}{$\begin{array}{l}\text { HIV-uninfected } \\
\qquad \mathbf{n}=7\end{array}$} \\
\hline & VVC & Colonization & VVC & Colonization \\
\hline & $\mathbf{n}$ & $\mathbf{n}$ & $\mathbf{n}$ & $\mathbf{n}$ \\
\hline C. albicans & 7 & 2 & 5 & 1 \\
\hline C. parapsilosis & 2 & 1 & 1 & 0 \\
\hline C. glabrata & 1 & 2 & 0 & 0 \\
\hline C. dubliniensis & 1 & 0 & 0 & 0 \\
\hline C.albicans + C. glabrata & 1 & 0 & 0 & 0 \\
\hline
\end{tabular}

VVC, vulvovaginal candidiasis. $\mathrm{p}<0.05, \chi^{2}$ test, Fisher's exact test.

Table 5. Minimal inhibitory concentrations $(\mathrm{mg} / \mathrm{L})$ of Candida spp.

\begin{tabular}{|c|c|c|c|c|c|}
\hline \multirow{2}{*}{$\begin{array}{l}\text { Candida species } \\
\mathbf{n}=25\end{array}$} & \multicolumn{5}{|c|}{ MIC median, mg/L, (min-max) } \\
\hline & Amphotericin B & Flucytosine & Fluconazole & Voriconazole & Caspofungin \\
\hline $\begin{array}{l}\text { C. albicans } \\
(\mathrm{n}=16)\end{array}$ & $\begin{array}{c}0.22 \\
(0.094-0.38)\end{array}$ & $\begin{array}{c}0.5 \\
(0.023->32)\end{array}$ & $\begin{array}{c}0.25 \\
(0.094-0.5)\end{array}$ & $\begin{array}{c}0.008 \\
(0.004-0.032)\end{array}$ & $\begin{array}{c}0.11 \\
(0.064-0.5)\end{array}$ \\
\hline $\begin{array}{l}\text { C. dubliniensis } \\
(\mathrm{n}=1)\end{array}$ & 0.064 & 0.004 & 0.094 & 0.006 & 0.19 \\
\hline $\begin{array}{l}\text { C. glabrata } \\
(\mathrm{n}=4)\end{array}$ & $\begin{array}{c}0.5 \\
(0.38-0.5)\end{array}$ & $\begin{array}{c}0.007 \\
(0.006-0.008)\end{array}$ & $\begin{array}{c}36 \\
(8->256)\end{array}$ & $\begin{array}{c}0.285 \\
(0.064-1)\end{array}$ & $\begin{array}{c}0.19 \\
(0.19-0.38)\end{array}$ \\
\hline $\begin{array}{l}\text { C. parapsilosis } \\
(\mathrm{n}=4)\end{array}$ & $\begin{array}{c}0.38 \\
(0.25-0.38)\end{array}$ & $\begin{array}{c}0.023 \\
(0.012-0.023)\end{array}$ & $\begin{array}{c}0.285 \\
(0.19-0.5)\end{array}$ & $\begin{array}{c}0.007 \\
(0.006-0.016)\end{array}$ & $\begin{array}{c}0.56 \\
(0.25-1)\end{array}$ \\
\hline
\end{tabular}


uninfected-control group. ${ }^{15}$ The prevalence of Candida spp. isolated from the vaginal mucosa is variable. In Italy, 16.8\% of HIV-infected women have Candida spp. in vaginal mucosa, ${ }^{10}$ while in the United States 35\% of HIV-infected women had vaginal positive culture for Candida spp. (EUA). ${ }^{18}$ Such variation could be explained by differences in the immune status of patients involved or by the presence of additional risk factors to Candida infection, such as a decreased number of CD4+ T-cells or concomitant antibiotic therapy. ${ }^{18}$

There is scant information about the frequency of non-albicans species in vaginal mucosa of HIV-infected women in Brazil. In the present study, C. albicans was the most frequent species isolated from the vaginal mucosa in both HIV-infected and uninfected women. In other countries such as Italy and the United States, the frequency was higher ranging from $81 \%$ to $92 \%$, compared to that found in our study (52.9\%). ${ }^{10,11,18}$ In HIV-uninfected patients, our data was similar to other studies performed in Brazil, which describe the prevalence of $C$. albicans isolated in vaginal samples ranging from $60 \%$ to $80 \%^{19,20}$ and in other countries where the prevalence of C. albicans in vaginal samples ranges between $80 \%$ to $90 \%{ }^{1,11,21,22}$ A higher diversity of non-albicans species was found in HIV-infected patients compared to uninfected controls. C. glabrata was the most frequent non-albicans species isolated in HIV-infected patients, followed by C. parapsilosis.

In accordance with other studies, there was no relationship found between symptoms and isolated yeast species. ${ }^{23}$ No correlation could be established between the level of CD4+ T-cell counts, the amount of HIV viral load, and the frequency of VVC in HIV-infected patients. These results were expected because of the observational nature of our study and the small sample size.

Regarding the susceptibility of Candida species to antifungal drugs, isolated yeasts were susceptible to Amphotericin B, Flucytosine, Voriconazole, and Caspofungin. Only three isolates had dose-dependent susceptibility or resistance to fluconazole, all of these were C. glabrata present in the vaginal mucosa of HIV-1-infected patients. These data are in agreement with other studies ${ }^{23-25}$ that described azole refractory vaginitis caused by non-albicans Candida, particularly by C. glabrata. ${ }^{23}$ Non-albicans Candida infections frequently require the use of non-azole therapy, including topical therapy with boric acid, Flucytosine, or Amphotericin B. ${ }^{24,26}$

In summary, our study found higher prevalence of Candida spp. in vaginal mucosa of HIV-infected patients than uninfected women. Thus, these patients could benefit from a periodic gynecological examination and VVC screening, even when undergoing HAART treatment. Although the species of C. albicans is the most frequent, it is evident the emergence of non-albicans Candida species, including C. glabrata with intrinsic resistance to azoles. Therefore, alternative agents to treat VCC caused by C. glabrata should be considered.

\section{REFERENCES}

1. Sobel JD, Faro S, Force RW et al. Vulvovaginal candidiasis: epidemiologic, diagnostic and therapeutic considerations. Am J Obstet Gynecol. 1998; 178:203-11.

2. Foxman B, Barlow R, D'Arcy H, Gillespie B, Sobel JD. Candida vaginitis: self-reported incidence and associated costs. Sex Transm Dis. 2000; 27(4):230-5.

3. Mardh PA, Rodrigues AG, Genc M et al. Facts and myths on recurrent vulvovaginal candidosis-a review on epidemiology, clinical manifestations, diagnosis, pathogenesis and therapy. Int J STD AIDS 2002; 13(8):522-39.

4. Schaller M. Candida albicans-interactions with the mucosa and the immune system. J Dtsch Dermatol Ges. 2006: 4(4):328-36.

5. Mendling W, Seebacher C. Guideline vulvovaginal candidosis: guideline of the German Dermatological Society, the German Speaking Mycological Society and the Working Group for Infections and Infectimmunology of the German Society for Gynecology and Obstetrics. Mycoses 2003; 46(9-10):365-9.

6. Linhares LM, Witkin SS, Miranda SD et al. Differentiation between women with vulvovaginal symptoms who are positive or negative for Candida species by culture. Infect Dis Obstet Gynecol. 2001; 9(4):221-5.

7. Rosa MI, Rumel D. Fatores Associados à Candidíase Vulvovaginal: Estudo Exploratório. Rev Bras Ginecol Obstet. 2004; 26(1):65-70

8. Barrenetxea Z. Vulvovaginitis candidiásica. Rev Iberoam Micol. 2002; 19(1):22-4.

9. Sebitloane M.H. HIV and gynecological infections. Best Pract Res Clin Obstet Gynaecol. 2005; 19(2):231-41.

10. Beltrame A, Matteelli A, Carvalho AC et al. Vaginal colonization with Candida spp. in human immunodeficiency virus-infected women: a cohort study. Int J STD AIDS 2006; 17(4):260-6.

11. Sobel JD, Ohmit SE, Schuman P et al. The evolution of Candida spp. and fluconazole susceptibility among oral and vaginal isolates recovered from human immunodeficiency virus (HIV)-seropositive and at-risk HIV-seronegative women. J Infect Dis 2001; 183:286-93

12. Spinillo A, Zara F, Gardella B et al. The effect of vaginal candidiasis on the shedding of human immunodeficiency virus in cervicovaginal secretions. Am J Obstet Gynecol. 2005; 192(3):774-9.

13. Shifrin E, Matityahu D, Feldman J, Minkoff H. Determinants of incident vulvovaginal candidiasis in human immunodeficiency virus-positive women. Infect Dis Obstet Gynecol. 2000; 8(3-4):176-80.

14. Gygax SE, Vermitsky JP, Chadwick SG et al. Antifungal resistance of Candida glabrata vaginal isolates and development of a quantitative reverse transcription-PCR-based azole susceptibility assay. Antimicrob Agents Chemother. 2008; 52(9):3424-6.

15. Grinsztejn B, Bastos FI, Veloso VG et al. Assessing sexually transmitted infections in a cohort of women living with HIV/AIDS, in Rio de Janeiro, Brazil. Int J STD AIDS 2006; 17(7):473-8.

16. Duerr A, Heilig CM, Meikle SF et al. Incident and persistent vulvovaginal candidiasis among human immunodeficiency virus-infected women: Risk factors and severity. Obstet Gynecol. 2003; 101(3):548-56.

17. Duerr A, Sierra MF, Feldman J et al. Immune compromise and prevalence of Candida vulvovaginitis in human immunodeficiency virus-infected women. Obstet Gynecol. 1997; 90(2):252-6. 
18. Williams A, Andrews S, Tashima K, Mezger J, Yu C. Factors associated with vaginal yeast infections in HIV-positive women. J Assoc Nurses AIDS Care 1998; 9(5):47-52.

19. Holanda A, Fernandes A, Bezerra $C$ et al. Candidíase vulvovaginal: sintomatologia, fatores de risco e colonização anal concomitante. Rev Bras Ginecol Obstet. 2007; 29(1):3-9.

20. Lopes Consolaro ME, Aline Albertoni T, Shizue Yoshida C et al. Correlation of Candida species and symptoms among patients with vulvovaginal candidiasis in Maringa, Parana, Brazil. Rev Iberoam Micol. 2004; 21(4):202-5

21. Novikova N, Rodrigues A, Mardh PA. Can the diagnosis of recurrent vulvovaginal candidosis be improved by use of vaginal lavage samples and cultures on chromogenic agar? Infect Dis Obstet Gynecol. 2002; 10(2):89-92.
22. Corsello S, Spinillo A, Osnengo G et al. An epidemiological survey of vulvovaginal candidiasis in Italy. Eur J Obstet Gynecol Reprod Biol. 2003; 110(1):66-72.

23. Ringdahl E. Treatment of recurrent vulvovaginal candidiasis. Fam Physician. 2000; 61(11) 3306-12, 17.

24. Sobel J. Vulvovaginitis due to Candida glabrata. An emerging problem. Mycoses 1998; 41(Suppl 2):18-22.

25. Richter SS, Galask RP, Messer SA et al. Antifungal susceptibilities of Candida species causing vulvovaginitis and epidemiology of recurrent cases. J Clin Microbiol 2005; 43(5):2155-62.

26. Hettiarachchi N, Ashbee HR, Wilson JD. Prevalence and management of non-albicans vaginal candidiasis. Sex Transm Infect 2010; 86(2):99-100. 